\title{
Practice of Kangoo Jumps Fitness to improve female students' cardiorespiratory fitness
}

\author{
Mokrova T. I. ${ }^{1 \mathrm{ABCDE}}$, Osipov A. Yu. ${ }^{1,2,5 \mathrm{ABCDE}}$, Kudryavtsev M. D. ${ }^{1,3,4,5 \mathrm{ABCDE}}$, Nagovitsyn R. S. ${ }^{6 \mathrm{BCDE}}$, Markov K. K. ${ }^{7 \mathrm{BCDE}}$ \\ ${ }^{1}$ Siberian Federal University, Russia \\ ${ }^{2}$ Krasnoyarsk State Medical University named after professor V.F. Voyno-Yasenetsky, Russia \\ ${ }^{3}$ Krasnoyarsk State Pedagogical University named after V.P. Astafiev, Russia \\ ${ }^{4}$ Reshetnev Siberian State University of Science and Technology, Russia \\ ${ }^{5}$ Siberian Law Institute of the Ministry of Internal Affair of Russia, Russia \\ ${ }^{6}$ Glazov State Pedagogical Institute named after V.G. Korolenko, Russia \\ ${ }^{7}$ National Research Irkutsk State Technical University, Russia
}

Authors' Contribution: A - Study design; B - Data collection; C - Statistical analysis; D - Manuscript Preparation; E - Funds Collection

\begin{abstract}
Purpose: $\quad$ Experts record the deterioration of the physical and cardiorespiratory fitness of students. Scientists recommend using fitness training in the practice of teaching students to increase cardiorespiratory fitness. The purpose of the research is to increase the level of cardiorespiratory fitness of female students by practicing Kangoo Jumps fitness in the practice of physical education.

Material: $\quad$ participants are female students $(n=53$, age - 19-20 years old). The study period was 10 months. Some females $(n=17)$ used Kangoo Jumps fitness in the practice of physical education. Indicators of physical and cardiorespiratory fitness were evaluated by the following methods: step test, Functional fitness assessment tests. Statistical data analysis was performed applying the Mann - Whitney $\mathrm{U}$ - test.

Results: $\quad$ The test results (step test) revealed a significant $(P<0.05)$ advantage of females practicing Kangoo Jumps fitness. The results are approximately the same for all females in most of the functional fitness assessment tests. The lowest weight gain (about $0.8 \mathrm{~kg}$ ) is shown by females who used Kangoo Jumps fitness. Body mass indexes (from 1.8 to $2 \mathrm{~kg}$.) were increased by students who used other types of fitness.

Conclusions: It was revealed the possibility of increasing the cardiorespiratory fitness level of female students practicing Kangoo Jumps fitness in the practice of physical education. It was found the ability to control the increase in body weight of females.

Keywords: $\quad$ wellness fitness, physical education, females, obesity prevention, Kangoo Jumps fitness.
\end{abstract}

\section{Introduction}

The level of physical activity and the dietary regime of majority students do not meet the recommendations of health experts. The data show a significant decrease in the participation of young people in regular motor activity [1, 2]. The growth of the sedentary lifestyle of young people is determined in another study [3]. The consequence is a significant increase in body weight and the development of obesity in many students [4]. These factors lead to various psychological disorders [5]. Regulatory programs of physical education in universities are not able to maintain indicators of body weight and physical fitness of students at an acceptable level $[6,7]$. Health experts recommend increasing the level of physical fitness by significantly increasing the level of aerobic fitness of students [8].

The functional fitness of the cardiorespiratory system is important in the factor model of the motor and functional activity of young people [9]. It is determined the statistically significant correlation between cardiorespiratory fitness and the practice of a healthy lifestyle [10]. The main motives of modern students to physical exercise and fitness are the following: a decrease in the percentage of body fat and increased aerobic fitness [11]. There is evidence of a significant positive effect of (c) Mokrova T. I., Osipov A. Yu., Kudryavtsev M. D., Nagovitsyn R. S., Markov K. K., 2019

doi:10.15561/20755279.2019.0405 aerobic exercises (fitness aerobics), implemented in the practice of physical education of students [12]. To achieve a positive effect requires a certain intensity [13], and a sufficient duration of exercise [14]. Practice shows that regular aerobic exercise has a positive effect on weight loss in students [15]. Aerobic exercise enhances the physical and psychological status of young people [16, 17]. The use of aerobic fitness training is recommended to untrained young people and young athletes $[18,19]$.

It was revealed a negative trend of reducing the level of aerobic readiness of students. This is due to the lack of daily physical activity [20]. The decrease in cardiorespiratory fitness indices was revealed even among students studying at the faculties of physical education and sport [21]. Scientists recommend using the correlation between the content of physical education programs, the level of physical activity and the behavioral regulation of students [22]. It was revealed the possibility of a significant increase in the level of physical development and the level of knowledge about the benefits of physical activity in young people practicing cardiorespiratory fitness in the practice of physical education [23].

Currently offered a large number of health and sports fitness. The practical use of types of fitness has significant differences [24]. In some types of modern sports fitness (in particular Latin American dances), the effectiveness in 
improving physical health wasn't completely determined [25]. There is evidence of the benefits of Zumba Fitness in increasing aerobic fitness in young women [26]. Found data on the possibility of practicing highintensity workouts and mixed aerobic-strength training of moderate-intensity to reduce body weight [27]. The step aerobics in the practice of physical education of female students was also considered as effective [28]. The physical education programs are actively applied In higher education institutions, including various types of recreational and sports fitness [29]. However, data monitoring of the students' physical condition shows a significant deterioration in the physical health indicators of the majority of students during the period of study [30]. Students consider their level of physical activity sufficient to maintain physical health at the proper level [31]. Changes are necessary for the practice of physical education of students to increase the level of physical activity. Increase of indicators of cardiorespiratory fitness of young people is also a priority task.

Kangoo Jumps fitness is a new type of fitness that is popular among young people. This type of fitness is the performance of various stepping, jumping and dance movements. All movements are performed at a fast pace and in special shoes - Kangoo Jumps boots [32]. These shoes reduce the risk of negative effects on the body in intensively performing jumping exercises [33]. To increase the level of physical performance, experts recommend to carry out Kangoo Jumps fitness classes at least 30 minutes long. The intensity of the movements should be high [34]. Scientists also point to the high efficiency of practicing Kangoo Jumps fitness in the practice of correcting body weight and prevention overweight [35] and obesity [36].

Other studies of practicing Kangoo Jumps fitness define:

- It is concluded that after running exercise on submaximal exercise with the use of equipment Kangoo Jumps had become favorable outcome for postural balance. One such reason would be because of its system of absorption and dissipation of impact, which allows a better activation of the proprioceptive system through increasing the speed of afferent estimate [33].

- Determinations from this preliminary evaluation of breath test during Kangoo Jumps exercise suggest that the Kangoo Jumps may reduce the oxidative stress, and Laser photoacoustic spectroscopy system provides a useful evaluation of ethylene biomarker (as a by-product of oxidative stress occurring inside the cells), being perfectly suitable to assessing the breath gases [36].

- This study revealed many types of knee MRI findings of asymptomatic Kangoo Jumpers compared to the control group. These MRI findings can predict and prevent possible acute knee injury or chronic joint problems like osteoarthritis [37].

- A Kangoo Jump class causes dehydration and rehydration strategies are necessary, however both water and sports drinks are sufficient for adequate rehydration [38].

- Training with Kangoo Jumps ${ }^{\mathrm{TM}}$ provides an effective means of improving aerobic capacity, while reducing the rate of injury when compared to training with normal running shoes [39].

- Comparison of kinematic parameters during the Hop Brasil class practicing Kangoo Jumps shoes and barefoot confirmed that ankle joint are under the heavy loads. The knee and hip joint are under the less loads [40].

Hypothesis. We assumed that the use of Kangoo Jumps fitness exercises in the practice of physical education will allow to achieve a higher level of cardiorespiratory fitness of females, compared with other programs of physical education of female students.

Purpose of the study. Search for the possibility of a significant increase in the cardiorespiratory fitness level of young people (19-20 years old) relatively healthy female students practicing Kangoo Jumps fitness method.

\section{Material and methods}

Participants: Young (19-20 years old) relatively healthy full-time female students $(\mathrm{n}=53)$. All the females underwent a medical examination and had no contraindications to exercise and fitness. All the females gave informed consent to participate in the research and publish the results. The selection of females was performed among a number of relatively healthy female students with similar indicators of physical activity. The selection was carried out among female students engaged in fitness - aerobics and athletic fitness (strength and cardiorespiratory training). The selection considers indicators of females' body weight. The females weighing from 50 to $52 \mathrm{~kg}$ were selected for studies. On average, the body mass indices of female students were $51.19 \pm$ $0.34 \mathrm{~kg}$.

\section{Research Design.}

The studies were conducted during one academic year (September 2018 - June 2019). At the beginning, the females passed the functional fitness assessment test [41].

Functional fitness assessment protocol and testing standards. The functional fitness assessment tests must be performed consecutively in the following order with the prescribed rest periods between tests. If one or more of the tests cannot be performed (e.g. pushups cannot be performed because of a shoulder injury, etc.) then the score must be entered as ZERO. If the aerobic fitness test is not performed, enter a time of 0 minutes and 0 seconds in one of the options (run, walk, row).

1. Aerobic Fitness Test (One Mile Run Test);

2. Rest 5 minutes;

3. Upper Body Strength/Endurance (Push-up) Test;

4. Rest 3 minutes;

5. Lower Body Strength/Endurance (Squat) Test;

6. Rest 3 minutes

7. Core Strength/Endurance (Plank) Test.

Females with approximately equal results were randomly divided into 3 approximately equal groups. Group number $1(\mathrm{n}=18)$ continued fitness aerobics. 
Group number $2(\mathrm{n}=18)$ continued to practice athletic fitness. Kangoo Jumps fitness exercise complexes were included in the program of group $3(n=17)$. The intensity of the load was estimated by the Polar A300 heart rate monitor. It was recorded the dynamics of the heart rate of female students. Limit values of the aerobic exercise intensity were $135-145 \mathrm{bpm}$. in the first and second months of classes; $145-150 \mathrm{bpm}$ in the 3rd and 4th months. Subsequently, the intensity of aerobic exercise was about $145-160 \mathrm{bpm}$. We found it inappropriate to further increase the intensity of aerobic exercise. Complaints were received from the females about fatigue and the inability to perform the exercises with higher intensity. It should be noted that the females practicing Kangoo Jumps fitness, showed a slightly higher ability to maintain a given intensity. Fitness aerobics and power fitness groups maintained an intensity of $150-160 \mathrm{bpm}$ no more than 16-19 minutes of the main part of the training. The group practicing Kangoo Jumps fitness maintained the intensity of $150-160 \mathrm{bpm}$. about $20-23 \mathrm{~min}$ of the main part of the training.

All the females were offered to attend regularly practical training on selected physical education programs. The number of classes -2 per week. The time for each class is $90 \mathrm{~min}$. Classes for females of group 1 and 3 consisted of aerobic fitness classes (40-45 min), strength training (20$30 \mathrm{~min}$ ), exercises for developing flexibility and mobility of joints (15-20 min). Group number 1 practiced fitness aerobics in the main part of the class (performing various dance moves on step platforms of a certain height with rhythmic music). Group 3 used Kangoo Jumps fitness in the main part of the class. Kangoo Jumps fitness is a dance, jump, stepping movements performed in special shoes (Kangoo Jumps boots) at a fast pace with rhythmic music.

The program of classes for females of group 2 consisted of physical training for strength (40-50 $\mathrm{min}$ ) and aerobic (20-30 min). Training devices (strength training), fitness cycles and treadmills (cardio). The exercises for the development of flexibility and mobility of the joints were also included in the program (15 $\mathrm{min})$.

To assess the level of females functional fitness were used: functional fitness assessment tests, step test. The step test represents the performing of ascents on a $40 \mathrm{~cm}$ high platform. The ascent rate is set by a special sound signal designed to provide at least 120 ascents per min. Testing time was 3 minutes. The level of functional fitness was determined by the time of pulsometry recovery in females to a state of rest.

We planned to evaluate the application effectiveness of the presented types of fitness in the prevention of obesity. All females were weighed weekly throughout the study period. It was evaluated the dynamics of fluctuations in the indicators of females body weight in 2 regular fitness classes per week.

Statistical analysis: To evaluate the results of the research, the authors applied the SPSS20 program. The level of reliability and significance of the obtained data are determined by the Mann - Whitney $\mathrm{U}$ - test.

\section{Results}

At the beginning of the research, all the females demonstrated approximately the same results of the functional fitness assessment tests. After 10 months, the results of the students in several tests significantly changed. In the "One Mile Run Test" $(1.6 \mathrm{~km})$, the results of the females of group 3 were significantly $(\mathrm{P}<0.01)$ higher than the results of females from other groups. In testing the "Push-up" arm muscles strength, significantly $(\mathrm{P}<0.05)$ higher results were found in the females of group 2 (athletic fitness). In the "Squat" test, the dynamics of the increase in results was found in students of all groups. The highest results were shown by females of group 3 (Kangoo Jumps fitness). Indicators of body balance (test "Plank") were approximately the same for all groups. Complete test results are presented in Table 1.

The assessment of female students' functional fitness (step-test) shows the dynamics of a significant $(\mathrm{P}<0.05)$

Table 1. The test results of female students for the period of research.

\begin{tabular}{|c|c|c|c|c|c|c|}
\hline \multirow{2}{*}{ Criteria } & \multicolumn{2}{|c|}{ Group №1 (n=18) } & \multicolumn{2}{|c|}{ Group №2 (n=18) } & \multicolumn{2}{|c|}{ Group №3 (n=17) } \\
\hline & September & June & September & June & September & June \\
\hline One Mile Rur & & & & & & \\
\hline $\begin{array}{l}\text { Test } \\
\text { (6.25 min) }\end{array}$ & $7.12 \pm 0.18$ & $6.42 \pm 0.08$ & $7.14 \pm 0.11$ & $6.44 \pm 0.13$ & $7.14 \pm 0.15$ & $6.34 \pm 0.09 *$ \\
\hline $\begin{array}{l}\text { Push-up } \\
\text { (40 times) }\end{array}$ & $17.08 \pm 1.34$ & $19.11 \pm 1.42$ & $17.26 \pm 1.13$ & $21.09 \pm 1.27^{* *}$ & $17.21 \pm 1.26$ & $19.43 \pm 1.39$ \\
\hline $\begin{array}{l}\text { Squat } \\
\text { (100 times) }\end{array}$ & $56.17 \pm 0.21$ & $63.21 \pm 2.18^{* *}$ & $56.31 \pm 0.25$ & $58.52 \pm 2.19$ & $55.98 \pm 0.46$ & $73.76 \pm 2.12^{*}$ \\
\hline $\begin{array}{l}\text { Plank } \\
\text { (2.5 min) }\end{array}$ & $1.29 \pm 0.02$ & $1.48 \pm 0.13$ & $1.28 \pm 0.09$ & $1.49 \pm 0.11$ & $1.28 \pm 0.04$ & $1.48 \pm 0.16$ \\
\hline Step-test & $3.42 \pm 0.16$ & $3.18 \pm 0.21$ & $3.43 \pm 0.35$ & $3.20 \pm 0.14$ & $3.42 \pm 0.54$ & $3.09 \pm 0.27^{* *}$ \\
\hline Body mass & $50.86 \pm 0.47$ & $52.57 \pm 0.29 * *$ & $51.38 \pm 0.64$ & $53.44 \pm 0.18^{*}$ & $51.33 \pm 0.46$ & $52.08 \pm 0.17$ \\
\hline
\end{tabular}

Note: * - P $<0.01$ - significance level; ${ }^{* *}-$ P $<0.05$ - significance level. 
decrease in recovery time for all females after a test load. In groups 1 and 2, it was revealed the significant improvement in recovery results: in group 1 , from 3.42 \pm 0.16 to $3.18 \pm 0.21 \mathrm{~min}$; in group 2 from $3.43 \pm 0.35$ to $3.20 \pm 0.14 \mathrm{~min}$. It was revealed the most significant decrease in the recovery time interval in females of group 3 . The recovery interval decreased from $3.42 \pm 0.54$ to $3.09 \pm 0.27 \mathrm{~min}$.

The studies revealed the dynamics of increase in body weight of females. In group 1 (fitness aerobics), a significant $(\mathrm{P}<0.05)$ increase in the average body weight of female students was recorded from $50.86 \pm 0.47 \mathrm{~kg}$ to $52.57 \pm 0.29 \mathrm{~kg}$. In group 2 (athletic fitness), the body mass indexes of females increased from $51.38 \pm 0.64 \mathrm{~kg}$ to $53.44 \pm 0.18 \mathrm{~kg}$. In group 3 (Kangoo Jumps fitness), the body mass indices of the females increased slightly from $51.33 \pm 0.46 \mathrm{~kg}$ to $52.08 \pm 0.17 \mathrm{~kg}$.

\section{Discussion}

It was revealed some lack of effectiveness of certain types of fitness in the practice of prophylaxis the increase in body weight and obesity. Studies revealed a significant (about $2 \mathrm{~kg}$ ) increase in the body mass values of female students practicing fitness aerobics and athletic fitness. The obtained results do not coincide with the data of scientists recommending mixed aerobic-power [27] and step-training [28] for the correction of the body weight of students. Experts emphasize the high efficiency of Kangoo Jumps fitness in the practice of weight control and prevention of obesity in young people. There is data of a decrease in body weight of students practicing Kangoo Jumps fitness, an average of $2 \mathrm{~kg}$ per 10 months [35]. We found a slight increase in body mass values (about 0.8 $\mathrm{kg}$ ) in females who practiced Kangoo Jumps fitness for 10 months. In our opinion, the difference between the results and the data of other scientists is a consequence of the insufficient number ( 2 classes per week) of fitness classes for females. The obtained data indicate that it is impossible to solve the problem of increasing the body mass of students within the standard physical education programs in universities. Only 2 fitness classes per week lead to increase in body mass of female students. Such female students demonstrate less weight gain [42].

The indicators of physical and functional fitness of students are influenced by the intensity of the exercises. In different types of fitness training (aerobics, dancing, step aerobics), the intensity of the exercises is different. There is data that most students perform $50 \mathrm{~min}$ of Zumba Fitness dance load at levels of light and moderate-intensity [26]. Self-selected exercise intensity is most beneficial for people practicing dance fitness training [12]. Fitness aerobics classes involve performing rhythmic dance movements to music with a certain level of intensity [28]. However, in the process of teaching female students to various dance movements, the intensity of the load is not high [32]. There is data concerning the targeted increase in the intensity of aerobic exercise in young people. This allows to achieve a significant health effect [42]. There is data of the necessity to practice Kangoo Jumps fitness not less than 30 min to increase the indices of physical fitness. The level of intensity of Kangoo Jumps fitness movements should be high [34]. In our studies, females of groups 1 and 2 could maintain a high intensity of aerobic training for only 16-19 $\mathrm{min}$. The frequency of heart contractions among female students of these groups reached 150-160 $\mathrm{bpm}$. Then the females complained of a high degree of fatigue and reduced the intensity of the exercises. Females practicing Kangoo Jumps fitness could maintain a high level of intensity - 150-160 bpm for a longer time - 20-23 min. In our opinion, the maintenance of a higher level of load's intensity was facilitated by special shoes - Kangoo Jumps boots. The springs reduced a little the females' efforts in jumping movements. We do not recommend practicing the high level of exercise intensity more than $150 \mathrm{bpm}$ during more than $20-25 \mathrm{~min}$, in the practice of female students training Kangoo Jumps fitness.

The results of the step-test for females of group 3 (Kangoo Jumps fitness) were significantly higher than the results of other female students. The recovery intervals of females practicing fitness aerobics and Kangoo Jumps fitness were compared in similar studies [32]. The results are different from our data. The higher indicators of female students recovery are determined in our research. The recovery rates for females in group 3 were better on average by $38 \mathrm{sec}$. We explain the differences in the results of a higher level of physical fitness of females in this group. The total load was also slightly different. The time of each fitness training in our groups was increased by $10-15 \mathrm{~min}$.

We explain the differences in the results of recovery between our fitness groups by the wide possibilities of Kangoo Jumps fitness influence on the cardiorespiratory fitness of female students. This effect is achieved through the practice of jumping exercises of sufficient intensity. Experts recommend the more active practice of jumping exercises to increase the aerobic performance of students [43].

There are studies on the positive experience of aerobic fitness in small groups of students (up to 5 persons). Also, scientists recommend applying a competitive method in organizing classes in mini-groups [12]. We have achieved an increase in cardiorespiratory and physical fitness without a competitive method. The number of females in groups was 17-18 persons. We emphasize the possibility of practicing aerobic fitness in quite large groups (2030 persons or more). However, it should be noted that Kangoo Jumps fitness classes have some difficulties. These difficulties are associated with a rather high price for shoes - Kangoo Jumps boots (\$ 350-470). Highquality repair of these shoes is also difficult. The training gym must have a flat floor and the required dimensions. These factors limit the number of students practicing Kangoo Jumps fitness.

\section{Conclusions}

1. Studies demonstrated the possibility of effective application of Kangoo Jumps fitness in the practice of physical education of female students. It is revealed the 
possibility of a significant increase in the cardiorespiratory fitness indices of females practicing Kangoo Jumps fitness.

2. It was found out that the 2 mixed (cardio-strength) class per week does not have sufficient effectiveness to achieve optimal body weight. However, Kangoo Jumps fitness classes proved more effective in slowing down the increase in the body mass of female students. Females show the lowest rates of body mass growth over the study period.

\section{Conflict of interest}

The authors of the article declare that there is no conflict of interest.

\section{References:}

1. Radu L, Fagaras S, Vanvu G. Physical activity index of female university students. Procedia - Social and Behavioral Sciences, 2015; 191: 1763-1766. https://doi.org/10.1016/j.sbspro.2015.04.375

2. Koryahin V, Blavt O. The Effectiveness of the Experimental Method of Control in the Physical Education of Students of Special Medical Groups with Cardiovascular Diseases on the State of Psychophysiological Functions. Teoria ta Metodika Fìičnogo Vihovannâ, 2017; 17(2): 67-78. https://doi.org/10.17309/tmfv.2017.2.1191

3. Calestin J, Bopp M, Bopp C, Papalia Z. College student work habits are related to physical activity and fitness. International Journal of Exercise Science, 2017; 10(7): 1009-1017.

4. Meckel Y, Galily Y, Nemet D, Eliakim A. Changes in weight indexes and aerobic fitness of physical education students over three years of college. Journal of Human Sport \& Exercise, 2011; 6(1): 112-121. https://doi.org/10.4100/jhse.2011.61.13

5. Yorks D, Frothingham C, Schuenke M. Effects of group fitness classes on stress of quality of life of medical students. The Journal of the American Osteopathic Association, 2017; 117: e17-e25. https://doi.org/10.7556/jaoa.2017.140

6. Koryahin V, Blavt O. Pedagogical Principles of Control in Physical Education of Students of Special Medical Groups. TeorîataMetodikaFìzičnogo Vihovannâ, 2017;17(3):107-116. https://doi.org/10.17309/tmfv.2017.3.1195

7. Kalina RM, Jagiello W. Non-apparatus, Quasi-apparatus and Simulations Tests in Diagnosis Positive Health and Survival Abilities. In: Ahram T, editor. Advances in Human Factors in Sports, Injury Prevention and Outdoor Recreation, Ahfe 2017. Advances in Intelligent Systems and Computing. 6032018. p. 121-128. https://doi.org/10.1007/978-3-319-60822-8_12

8. Clark B, White $\mathrm{M}$, Royer N, Burlis $\mathrm{T}$, DuPont $\mathrm{N}$, Wallendorf $\mathrm{M}$, et al. Obesity and aerobic fitness among urban public school students in elementary, middle, and high school. Plos ONE, 2015; 10(9): e0138175. https://doi.org/10.1371/journal.pone.0138175

9. Mokrova T, Osipov A, Kudryavtsev M, Nagovitsyn R. Modern types of fitness practices in academic physical education (Kangoo-Jump Fitness). Teoriya $i$ Praktika Fizicheskoy Kultury, 2019; 7: 104-110.

10.Li Y, Wang S, Yu Y, Wu L, Shi Y, Zhang M, et al. Associations among physical education, activity-related healthy lifestyle practices, and cardiorespiratory fitness of Chinese youth. Research Quarterly for Exercise and Sport, 2019; 90(2): 123-132. https://doi.org/10.1080/02701367.2019.1603772

11.Bergman S. University students' exercise behavioral regulation, motives, and physical fitness. Perceptual and Motor Skills, 2013; 116(1): 322-339. https://doi.org/10.2466/06.10.PMS.116.1.322-339.

12.Shirobakina E, Andreenko T, Tkacheva E. Experience with interactive educational technology at fitness aerobics classes. Teoriya i Praktika Fizicheskoy Kultury, 2016; 5: 61-70.

13.Buscombe R, Inskip $H$. Affective change as a function of exercise intensity in a group aerobics class. Journal of Exercise Science \& Fitness, 2013; 11(1): 42-49. https://doi.org/10.1016/j.jesf.2013.04.001

14.Mustedanagić J, Bratić M, Milanović Z, Pantelić S. The effect of aerobic exercise program on the cardiorespiratory fitness and body composition of female college students. Facta Universitatis. Series: Physical Education and Sport, 2016; 14(2): 145-158.

15.Said M, Abdelmoneem M, Almaqhawi A, Kotob A, Alibrahim M, Bougmiza I. Multidisciplinary approach to obesity: Aerobic or resistance physical exercise? Journal of Exercise Science \& Fitness, 2018; 16(3): 118-123. https://doi.org/10.1016/j.jesf.2018.11.001

16.Siqiang G. Experimental study of aerobic exercise on the weight loss effect of obese female college students. Biomedical Research, 2018; (Special Issue): S193-S196. https://doi.org/10.4066/biomedicalresearch.29-17-828

17.Rovnaya OA, Podrigalo LV, Aghyppo OY, Cieslicka M, Stankiewicz B. Study of Functional Potentials of Different Portsmanship Level Synchronous Swimming Sportswomen under Impact of Hypoxia. Research Journal of Pharmaceutical Biological and Chemical Sciences. 2016;7(4):1210-1219.

18.Kozina Z, Sobko I, Ulaeva L, Safronov D, Boichuk Y, Polianskyi A, et al. The impact of fitness aerobics on the special performance and recovery processes of boys and girls 16-17 years old engaged in volleyball. International Journal of Applied Exercise Physiology, 2019; 8(1): 98-113. https://doi.org/10.30472/ijaep.v8i1.306

19.Jagiello W, Jagiello M, Kalina RM, Barczynski BJ, Litwiniuk A, Klimczak J. Properties of body composition of female representatives of the Polish national fencing team - the sabre event. Biology of Sport. 2017;34(4):401-406. https://doi.org/10.5114/biolsport.2017.70526

20.Mazerat N, Bellar D, Judge L, Brignac A, Smith J, Trosclair D. Relationship between exercise habits and age of college students. Journal of Strength and Conditioning Research, 2011; 25: S98-S99. https://doi.org/10.1097/01.JSC.0000395735.34933.4f

21.PrebegG,MihajlovićN,MitićD.Aerobicfitnesstrendofstudents of the faculty of sport and physical education at the University of Belgrade. Exercise and Quality of Life, 2012; 4(2): 41-47. https://doi.org/10.5937/exquli1202041P

22.Sibley B, Bergman S. Relationships among goal contents, exercise motivations, physical activity, and aerobic fitness in university physical education courses. Perceptual and Motor Skills, 2016; 122(2): 678-700. https://doi.org/10.1177/0031512516639802

23.Chen $\mathrm{S}, \mathrm{Gu} \mathrm{X}$. Effects of cardiorespiratory fitness and weight status on knowledge of physical activity and fitness, attitude toward physical education, and physical activity. BMC Public Health, 2018; 18(1). 
https://doi.org/10.1186/s12889-018-5176-4

24.Paoli A, Bianco A. What is fitness training? Definitions and implications: A systematic review article. Iranian Journal of Public Health, 2015; 44(5): 602-614.

25.DomeneP,MoirH,PummellE,EastonC.SalsadanceandZumba fitness: Acute responses during community-based classes. Journal of Sport and Health Science, 2016; 5(2): 190-196. https://doi.org/10.1016/j.jshs.2015.04.004

26. Marques E, Ferreira J, Carvalho J,FigueiredoP. Cardiovascular demands and training load during a Zumba ${ }^{\circledR}$ session in healthy adult women. Science \& Sports, 2017; 32(6): e235-e243. https://doi.org/10.1016/j.scispo.2017.08.002

27.Carneiro M, de Oliveira A, Martins F, Souza P, Nunes P, Orsatti F. High-intensity interval body weight training promotes different adaptations to combined training in body composition and muscle strength in young women. Science \& Sports, 2018; 33(3): e105-e113. https://doi.org/10.1016/j.scispo.2017.11.001

28.Trukhachev V, Osychenko M, Skripkin V. Effect of different types of fitness aerobics on physical and functional state of female students. Teoriya i Praktika Fizicheskoy Kultury, 2015; 11: 55-58.

29. Vashchuk L, Dedeliuk N, Roda O, Kalytka S, Demianchuk $\mathrm{O}$, Matskevych $\mathrm{N}$, et al. The realization of the individual fitness programs in the physical education of high schoolgirls. Physical Activity Review, 2018; 6: 144-150. https://doi.org/10.16926/par.2018.06.19

30.Wang J. The association between physical fitness and physical activity among Chinese college students. Journal of American College Health, 2019. https://doi.org/10.1080/07448481.2018.1515747

31.Fagaras S, Radu L, Vanvu G. The level of physical activity of university students. Procedia - Social and Behavioral Sciences, 2015; 197: 1454-1457. https://doi.org/10.1016/j.sbspro.2015.07.094

32.Mokrova T, BryukhanovaN, OsipovA, ZhavnerT, LobinevaE, et al. Possible effective use of Kangoo Jump complexes during the physical education of young students. Journal of Physical Education and Sport, 2018; 18(Supplement issue 1): 342-348. https://doi.org/10.7752/jpes.2018.s146

33. Oliveira R, Oliveira P, Szezerbaty S, Oliveira L, Almeida $J$, et al. Effect of running exercise with and without the use of equipment Kangoo Jumps, in postural control: a case study. Manual Therapy, Posturology \& Rehabilitation Journal, 2014; 12: 131-135. https://doi.org/10.17784/mtprehabjournal.2014.12.179

34.Baltaretu I. Physical activity and emotional life adjustments - a study of Kangoo Jumps training effects. Romanian Journal of Experimental Applied Psychology, 2015; 6(1): 74-87.

35.Cosma J, Dimitru R, Lica E, Albina A, Cosma A. Aerobic gymnastics on Kangoo-jumps boots and its impact on students' fitness. Science, Movement and Health, 2015; XV(2, Supplement): 294-299.

36.Popa C, Patachia M, Banita S, Dumitras D. Exertion in Kangoo Jumps aerobic: evaluation and interpretation using spectroscopic technique determinations. Journal of Spectroscopy, 2013; Article ID 602434. http://dx.doi.org/10.1155/2013/602434

37.Polat B, Aydın D, Polat AE, Gürpınar T, Özmanevra R, Dirik MA. Evaluation of the Knees of Asymptomatic Kangoo Jumpers with MR Imaging. Magnetic Resonance in Medical Sciences, 2019. https://doi.org/10.2463/mrms.mp.2018-0094

38.da Silva GF, da Silva CP, Martins JB. Hydration status and performance comparation through of rehydration with sports drink and flavor water during kangoo jump class. RbneRevista Brasileira De Nutricao Esportiva. 2017;11(66):743755.

39. Miller NS, Taunton JE, Rhodes EC, Zumbo BD, Fraser S. Effects of a 12-week aerobic training program utilizing kangoo jumps???: Medicine \& Science in Sports \& Exercise, 2003;35:S372. https://doi.org/10.1097/00005768-200305001-02068

40.Juliane Cristine Lopes dos Santos, Paulo Dias da Costa, Mateus Rossato, Ewertton de Souza Bezerra, Rodrigo Ghedini Gheller, João Otacílio Libardoni dos Santos, Felipe P Carpes. Alterações na cinemática do membro inferior durante exercícios de ginástica com botas kangoo jumps ${ }^{\circledR}$. [Changes in lower limb kinematics during gymnastic exercises with kangoo jumps ${ }^{\circledR}$ boots]. October 2014. Laboratory of Neuromechanics, Federal University of Pampa, Uruguaiana, RS, Brazil. Scientific reports. (In Portuguese)

41.Functional fitness assessment protocol and testing standards. [Internet]. [updated 2019 April 4; cited 2019 Jun 01]. Available from: https://www.wellnessandprevention.com/ common/functional_fitness_testing_standards.pdf

42.McDonald S, Trost $\mathrm{S}$. The effects of a goal setting intervention on aerobic fitness in middle school students. Journal of Teaching in Physical Education, 2015; 34(4): 576-587. https://doi.org/10.1123/jtpe.2014-0138

43. Chen Ch-Ch, Lin Sh-Ye. The impact of rope jumping exercise on physical fitness of visually impaired students. Research in Developmental Disabilities, 2011; 32(1): 25-29. https://doi.org/10.1016/j.ridd.2010.08.010 


\section{Information about the authors:}

Mokrova T.I.; http://orcid.org/0000-0001-9544-1674; tanyabaulina@rambler.ru; Siberian Federal University; 79 Svobodny pr., Krasnoyarsk, 660041, Russia.

Osipov A.Yu.; http://orcid.org/0000-0002-2277-4467; ale44132272@yandex.ru; Siberian Federal University; 79 Svobodny pr., Krasnoyarsk, 660041, Russia; Krasnoyarsk State Medical University named after professor V.F. Voyno-Yasenetsky; P. Zeleznyak, 1, Krasnoyarsk, 660022, Russia; Siberian Law Institute of the Ministry of Internal Affair of Russia; Rokossovskia Street, 20, Krasnoyarsk, 660131, Russia; Reshetnev Siberian State University of Science and Technology; Office A-406, 31, Krasnoyarsky Rabochy Av., 660014, Krasnoyarsk, Russia.

Kudryavtsev M.D.; (Corresponding author); http://orcid.org/0000-0002-2432-1699; kumid@yandex.ru; Siberian Federal University; 79 Svobodny pr., Krasnoyarsk, 660041, Russia.; Siberian Law Institute of the Ministry of Internal Affair of Russia; Rokossovskia Street, 20, Krasnoyarsk, 660131, Russia; Krasnoyarsk State Pedagogical University of V.P. Astafyev; Ada Lebedeva Street 89, Krasnoyarsk, 660049, Russia.

Nagovitsyn R.S.; http://orcid.org/0000-0003-4471-0875; gto18@mail.ru; Glazov State Pedagogical Institute named after V.G. Korolenko; Pervomaiskaya Street, 25, Glazov, 427620, Russia.

Markov K.K.; http://orcid.org/0000-0003-1893-5907; k_markov@mail.ru; National Research Irkutsk State Technical University; Lermontova Street, 83, Irkutsk, 664074, Russia.;

\section{Cite this article as:}

Mokrova TI, Osipov AYu, Kudryavtsev MD, Nagovitsyn RS, Markov KK. Practice of Kangoo Jumps Fitness to improve female students' cardiorespiratory fitness. Physical education of students, 2019;23(4):191-197. https://doi.org/10.15561/20755279.2019.0405

This is an Open Access article distributed under the terms of the Creative Commons Attribution License, which permits unrestricted use, distribution, and reproduction in any medium, provided the original work is properly cited http://creativecommons.org/licenses/by/4.0/deed.en

Received: 04.06.2019

Accepted: 15.07.2019; Published: 28.08.2019 